\title{
The adoption of Chronic Fatigue Syndrome/Myalgic Encephalomyelitis case definitions to assess prevalence: A systematic review
}

\author{
Johnston, S1, Brenu EW11, Staines DR 1,2, Marshall-Gradisnik, S1
}

1 Griffith Health Institute, School of Medical Sciences, National Centre for Neuroimmunology and Emerging Diseases, Griffith University, Parklands, QLD, Australia

2 Gold Coast Public Health Unit, Queensland Health, Robina, QLD, Australia

Correspondence: Samantha Johnston, National Centre for Neuroimmunology and Emerging Diseases, Centre for Medicine and Oral Health, Griffith University, Southport, QLD, Australia, 4215; Phone: +617 56780414; Fax: +617 55528908; Email: samantha.johnston3@griffithuni.edu.au

Word count: 3,064 (including references) Abstract word count: 210 (including references)

Tables: 1

Figures: 1 


\section{Abstract}

Purpose: $\quad$ Prevalence estimates have been based on several case definitions of Chronic Fatigue Syndrome (CFS). The purpose of this paper is to provide a rigorous overview of their application in prevalence research.

Methods: A systematic review of primary studies reporting the prevalence of CFS since 1990 was conducted. Studies were summarized according to study design, prevalence estimates, and case definition used to ascertain cases.

Results: $\quad$ Thirty one studies were retrieved and eight different case definitions were found. Early estimates of CFS prevalence were based on the 1988 CDC [1], Australian [2], and Oxford [3]. The 1994 Centers for Disease Control and Prevention (CDC) [4] however, has been adopted internationally, as a general standard. Only one study has reported prevalence according to the more recent, Canadian Consensus Criteria (CCC) [5]. Additional estimates were also found according to definitions by Ho-Yen [6], the 2005 CDC empirical definition [7], and an epidemiological case definition (ECD) [8].

Conclusion: Advances in clinical case definitions during the past 10 years such as the CCC [5] has received little attention in prevalence research. Future assessments of prevalence should consider adopting more recent developments, such as the newly available International Consensus Criteria (ICC) [9]. This could improve the surveillance of more specific cases found within CFS.

Key words: $\quad$ Chronic Fatigue Syndrome; Myalgic Encephalomyelitis; Systematic Review; Prevalence; Case definition

Selected abbreviations and acronyms: CFS, Chronic Fatigue Syndrome; ME, Myalgic Encephalomyelitis; CDC, Centers for Disease Control and Prevention; CCC, Canadian Consensus Criteria; ICC, International Consensus Criteria 


\section{Introduction}

Chronic Fatigue Syndrome (CFS) represents a complex illness that has traditionally been described as debilitating fatigue, accompanied by a combination of symptoms. In the absence of a biological marker for the illness, case definitions have remained the predominant tool used to ascertain cases for clinical and epidemiological research. The first case definition for CFS was released in 1988 by the Centers for Disease Control and Prevention (CDC) [1]. It described all the clinical characteristics of what was known as chronic Epstein-Barr virus syndrome, but a link with the virus itself could not be established. Hence, the CDC proposed the term CFS for the illness, to remove the association with Epstein-Barr virus [1]. Accordingly, the 1988 CDC [1] described a new onset of debilitating fatigue of at least 6 months, accompanied by a minimum of eight, mostly flu like symptoms.

The Australian definition released in 1990 [2], included the same requirements for fatigue, accompanied by neuropsychiatric symptoms such as short term memory loss and difficulties concentrating. This was shortly followed by definitions from researchers in the United Kingdom, who maintained interest in a causal relationship with an infection. A definition by Ho-yen proposed in 1990 [6], is similar to the Australian [2], but required supporting evidence from case history, or clinical/laboratory evidence of a possible viral infection. The 1991 Oxford definition [3] on the other hand, only required the presence of debilitating fatigue for 6 or more months for CFS. It also featured additional criteria for a subset of CFS that it referred to as Post-Infectious Fatigue Syndrome. This required laboratory confirmation of an infectious agent.

In 1994, the CDC revised its 1988 definition [1]. It maintained criteria for fatigue, but reduced the required number of symptoms to four of the following: post-exertional malaise; unrefreshing sleep; impairment of short-term memory or concentration; muscle pain; joint pain; headaches; tender lymph

nodes; and sore throat [4]. This has remained the current definition of the CDC, despite their development of an empirical definition in 2005 [7]. This definition introduced the use of three standard 
measures to fulfill the same criteria of the 1994 definition [4], according to: symptoms using the CFS Symptom Inventory [10]; disability using the Short Form 36 survey [11]; and fatigue using the Multidimensional Fatigue Inventory [12]. The use of standard measures has also been proposed in an epidemiological case definition (ECD) published by UK researchers in 2007 [8] for severe fatigue, a reduction in pre-illness activity, myalgia, muscle weakness, joint pain, and swollen lymph nodes.

While many of these definitions were developed to select adult cases in a research setting, advances have been made in definitions for use in clinical diagnosis. In 2003, the Canadian Consensus Criteria (CCC) [5] was released. As studies were found to also refer to Chronic Fatigue Syndrome as Myalgic Encephalomyelitis, the definition adopted the hybrid term Myalgic Encephalomyelitis/Chronic Fatigue Syndrome (ME/CFS) to describe the illness. It also suggested that a reduced the duration of illness of 3 months would be appropriate for diagnosing cases in children, compared to 6 months for adults. It included some of the symptoms described in the 1994 CDC such as fatigue, post-exertional malaise, sleep dysfunction, and pain; but introduced additional symptoms relating to neurocognitive, autonomic, neuroendocrine and immune manifestations [5]. In doing so, it described an illness that affects multiple systems of the body.

A revised version became available in 2011, and renamed the International Consensus Criteria (ICC) [9]. Moving away from the previous hybrid model of ME/CFS, it suggested that ME be recognized as a distinct illness by removing those that fulfill the ICC, from the broader category of CFS described in previous definitions $[1-4,7]$. Accordingly, a number of significant changes were made. Duration of illness was no longer required, and the symptoms of chronic fatigue and post-exertional malaise commonly used to describe CFS, were replaced with a set of criteria for post-exertional neuroimmune exhaustion (PENE). Additional symptoms were reclassified under three categories of neurological impairment; immune or gastro-intestinal or genitourinary impairment; and energy metabolism or transport impairments. It is also the first definition to introduce several categories for severity, and more specific criteria for the diagnosis of cases in children. 
Prevalence assessment specific for CFS commenced with the release of the 1988 CDC definition, and has since relied on the quality of definitions that are available. When interpreting prevalence estimates, it is therefore important to understand the substantial differences that are found between definitions in terms of the symptoms they emphasize, and inclusion criteria. The purpose of this systematic review is to provide a rigorous overview on reported CFS prevalence, according to the case definitions used. It is particularly interested in whether prevalence studies have incorporated new developments in clinical definitions into their design. This will help evaluate the reliability of available estimates and how the role of case definitions in future surveillance of the illness can be improved.

\section{Methods}

Medline, Embase and PubMed Central databases were systematically searched using the Medical Subject Headings (MeSH) terms of 'Chronic Fatigue Syndrome' (which also captures Myalgic Encephalomyelitis) and 'prevalence'. Titles and abstracts were screened for potential studies whose primary outcome was to detect the prevalence of CFS in community or primary care samples. Full texts were then examined for suitability. Secondary search then commenced on reference lists of the studies selected for review. To capture the beginning of prevalence research and the progress of different countries, no restrictions were made to the date and language if detailed summaries in English were available. As this review focuses on CFS prevalence in the general population, it did not include assessment in groups of special interest. Data were summarized according to sample setting (community, primary care), sampling method (prospective vs. retrospective), age, estimated prevalence, and the case definition used to ascertain cases. 


\section{Results}

\section{Literature search}

The search returned 218 records, including 40 prevalence studies that were assessed for eligibility. Of these 9 exclusions were made: one study was based on a case-control design that was considered bias for determining prevalence [13]; one study that did not disclose which definition they used [14]; and 7 studies based on special interest groups [15-21]. The remaining 31 studies contributed a total of forty-one prevalence estimates, and were published between 1990 and 2011 (Table 1). Of these, 19 were community based [22-40]; 12 were primary-care based [2, 41-51]. Twenty nine were prospective $[2,22-49,51]$ and 2 retrospective $[24,50]$. Twenty five studies assessed cases in adults $[2,23-25,27$, 28, 30, 32, 33, 35-45, 47-51]; and 7 studies assessed cases specifically in children and adolescents (<18 years) $[22,26,29,31,34,36,46]$.

\section{Case definitions identified}

In total, eight different definitions have were identified in the studies (Table 1): the 1988 CDC [1], Australian [2], Ho-Yen [51], Oxford [3], the 1994 CDC [4], the 2005 CDC empirical [7], the CCC [5], and ECD [8]. This does not include approximate versions of the 1988 CDC [50], and 1994 CDC [24] definitions. In adult studies: eight estimates [35, 39, 40, 44, 45, 48, 49, 52] are based on the 1988 CDC [1]; three estimates [2, 35, 49] according to the Australian [2]; four estimates [35, 39, 47, 49] based on the Oxford [3], and only one estimate [51] based on the Ho-Yen [6]. Since 1997, 20 estimates [22, 23, $25,26,28-39,41-43$ ] are available using the 1994 CDC [4]. Only one prevalence estimate is available for each of the $2005 \operatorname{CDC}$ empirical [7, 27], the CCC [5, 41] and the ECD [8, 41] definitions. After the publication of these studies, the ICC [9] became available. 
Of these, four studies applied several definitions to report prevalence. Bates et al. [49] reported estimates of $0.3 \%$ (1988 CDC [1]), $0.4 \%$ (Oxford [3]) and 1.0\% (Australian [2]). Kawakami et al. [39] estimated prevalence of $1.50 \%$ for both the Oxford [3] and Fukuda definitions [4], while no cases fulfilled the 1988 CDC [1]. Lindal et al. [35] reported estimates of 4.8\% (Australian [2]), 2.4\% (Oxford [3]), 1.4\% (1994 CDC [4]) and 0\% (1988 CDC [1]). Lastly, Nacul et al. [41] produced estimates of 0.19\% (1994 CDC [4]), 0.11\% (CCC [5]) and 0.03\% (ECD [8]).

In studies based on children and adolescents, one [52] was based on the 1988 CDC [1]; the remaining six [22, 26, 29, 31, 34, 36] applied the 1994 CDC [4] and were published after the CCC [5] was released. One of the studies based on the 1994 CDC [4] reported 2 estimates of prevalence at baseline of $0.1 \%$ and at 6 months of $0.5 \%$ [26].

\section{Discussion}

\section{Case definitions in available prevalence}

This review found eight different case definitions have been used to report the prevalence of CFS. Inconsistent case definitions is predominant among the early studies and the variability this has caused in estimates is demonstrated by several studies [35, 39, 41, 49]. When compared to the 1994 CDC [4], Australian [2], and Oxford [3] definitions, the 1988 CDC [1] appears to have the lowest sensitivity, as it reports the lowest prevalence estimates [35, 39, 49]. The 1988 CDC [1] definition received particular criticism for its emphasis on fatigue, thereby not distinguishing CFS from other illnesses with unexplained fatigue [53]. Straus et al. [54] in particular, found that this led to the inadvertent selection of cases with high levels of psychiatric illness. The 1988 CDC [1] criteria for fatigue has also remained an issue, as it was adopted by subsequent definitions for CFS [2-6].

The Australian definition [2] was used to report the first formal prevalence estimate of CFS. Its symptom criteria is the most broad of the definitions, which has contributed to prevalence estimates at least two 
times higher [35, 49] than the 1988 CDC [1], Oxford [3], and 1994 CDC [4] definitions. This, combined with an emphasis on neuropsychiatric symptoms has also meant the definition is bias in selecting cases with psychiatric disorders [55]. The Ho-yen [6] and Oxford [3] definitions aimed to address the low sensitivity of the $1988 \mathrm{CDC}[1]$ criteria by requiring only two compulsory symptoms, as well as the overly inclusive criteria of the Australian [2] with additional laboratory confirmation of an infection. These definitions however, still lacked specificity, as many non-CFS cases with a post-viral illness could fulfill these criteria for CFS [56]. There also remains no consistent evidence that CFS shares a causal relationship with a virus [57].

As psychiatric disorders were identified as important source of confounding in CFS studies, the 1994 CDC [4] aimed to provide further clarification between the relationship of CFS and neuropsychiatric symptoms. It soon replaced previous definitions as studies adopted the 1994 CDC [4] as a general standard. This has enabled the comparison of prevalence estimates across geographies and sample settings. Its use in the past 10 years has remained consistent, despite the introduction of several new case definitions.

It is argued however, that the definition is still limited by its specificity, leading to the inconsistent selection of cases for research [58]. This is reflected in the observed variability found in reported prevalence estimates based on the 1994 CDC [4], that range between $0.19 \%$ [41] to $2.1 \%$ [42]. Some of these estimates however, are reported as the prevalence of "CFS-like" illness rather than true cases of CFS, to characterize cases that fulfill the criteria by self-reporting $[25,32,38]$. Further investigation on the specificity of the 1994 CDC definition [4] however, has found significant differences in simple clinical measurements between distinct clinical that all fulfilled the definition for CFS [59]. Further, it has been demonstrated that the definition was unable to distinguish between symptoms of post-exertional malaise, problems with sleep, memory and cognitive difficulties between cases of CFS and depression [60]. 
There are also concerns that a lack of explicit instructions has contributed to the inconsistent application of the definition [61]. This could be a reason for inflated estimates of CFS. A self-reporting survey in Hong Kong for example, reported prevalence as high as $6.4 \%$ in the community [30]. Moreover, a retrospective study was found to apply an approximate version of the 1994 CDC [4] to a national health survey, and reported a prevalence of $2.3 \%$ [24]. This version only included the presence of fatigue accompanied by concentration and/or short term memory difficulties, sleep issues, and pain. This only meets three of the eight possible symptoms specified in the 1994 CDC [4]. Therefore, caution must be taken when interpreting estimates of studies not only in the specificity of the definition used, but the methods used to apply them.

The 1994 CDC [4] has also received criticism for being revised by consensus rather than by new empirical findings [62]. The CCC [5] definition for ME/CFS however, was the first definition to devise its criteria from empirical evidence. Compared to the 1994 CDC [4], the CCC [5] has been shown to be more effective at selecting CFS cases with less psychiatric disorders, and more severe impairments in physical functioning, fatigue, neuropsychiatric, and neurological symptoms [63]. This is supported by the results of the only prevalence study to apply the CCC [5], where cases fulfilling the CCC [5] represented a distinct subgroup of 1994 CDC cases with more severe physical and cognitive symptoms [41].

Unlike the CCC definition [5] that has been shown to contribute more conservative prevalence estimates of CFS [41] than the 1994 CDC [4], the 2005 CDC empirical definition [7] has been attributed to significantly higher estimates of CFS [64]. Compared to one study reporting a prevalence of $0.4 \%$ in the United States (US) [37], a study that applied the 2005 CDC empirical [7] reported a US prevalence of $2.54 \%$ [27]. A suggested reason for this inflation is the 2005 CDC empirical [7] is more broad than the 1994 CDC [4], increasing its likelihood of including cases of psychiatric disorder [64]. This has been demonstrated in one study that found it misclassified $38 \%$ of diagnosed cases of Major Depressive Disorder as CFS [65]. Compared to the 2005 CDC empirical [7], the CCC [5] has also been 
shown to more effectively discriminate between cases and non-cases of CFS; the 2005 CDC empirical [7] could only discriminate $79 \%$ of cases, while the CCC [5] was able to discriminate between $87 \%$ of cases [66].

Further, all prevalence studies of CFS in children and adolescents identified in this review $[22,29,31$, $34,36,52]$, have been based on definitions for adults [1, 4]. Its inability to adequately identify cases in children may be reflected in the results found by one study, who a reported higher prevalence of the illness after 6 months [26]. A lack of specific criteria may lead to the selection of cases whose conformity to the definition changes over time.

Although the CCC [5] definition was the first to adapt its criteria for use in children, it was still predominantly aimed at diagnosis in adults. Concerns about the inability to distinguish cases in children led to the development of the Pediatric Case Definition for ME/CFS [67]. Findings have suggested that it can distinguish between those with the illness and controls [68]. It has yet to be published in prevalence research.

The latest definition used in prevalence studies is the ECD [8], however the prevalence estimates were significantly lower than the 1994 CDC [4], and CCC [5] suggesting the case definition does not have the sensitivity required to provide valid estimates of CFS [41].

\section{Case definitions in future prevalence}

The findings of the review highlight several important issues in the development of prevalence studies.

1) Since definitions have changed over time, early estimates cannot be compared to recent ones. Accordingly, it is not possible to measure accurately how prevalence has changed over time. 2) The 1994 CDC [4] remains a standard definition for CFS, despite concerns about its limited specificity. This could be a potential source of bias in reporting prevalence. 3) Available reports of prevalence in children and adolescents may not be reliable, because they are based on criteria for adults. 
Findings based on the CCC [5], indicate that it possesses the improved specificity needed in case definitions for research. A plausible reason for its late adoption in prevalence assessment is that it was primarily devised for clinical diagnosis. It relies on clinical verification of symptoms, as well as a laboratory protocol, which requires more resources to administer in a research setting. The current issues found in prevalence research however, may be improved through the adoption of such clinical definitions. It is proposed that the latest ICC definition for ME [9] be examined for its effectiveness in prevalence assessment. If systematically applied with the 1994 CDC, it could determine whether CFS has failed to capture more distinct cases of ME. The potential of the ICC [9] to select further subgroups for research in contrast to the 1994 CDC is displayed in Figure 1.

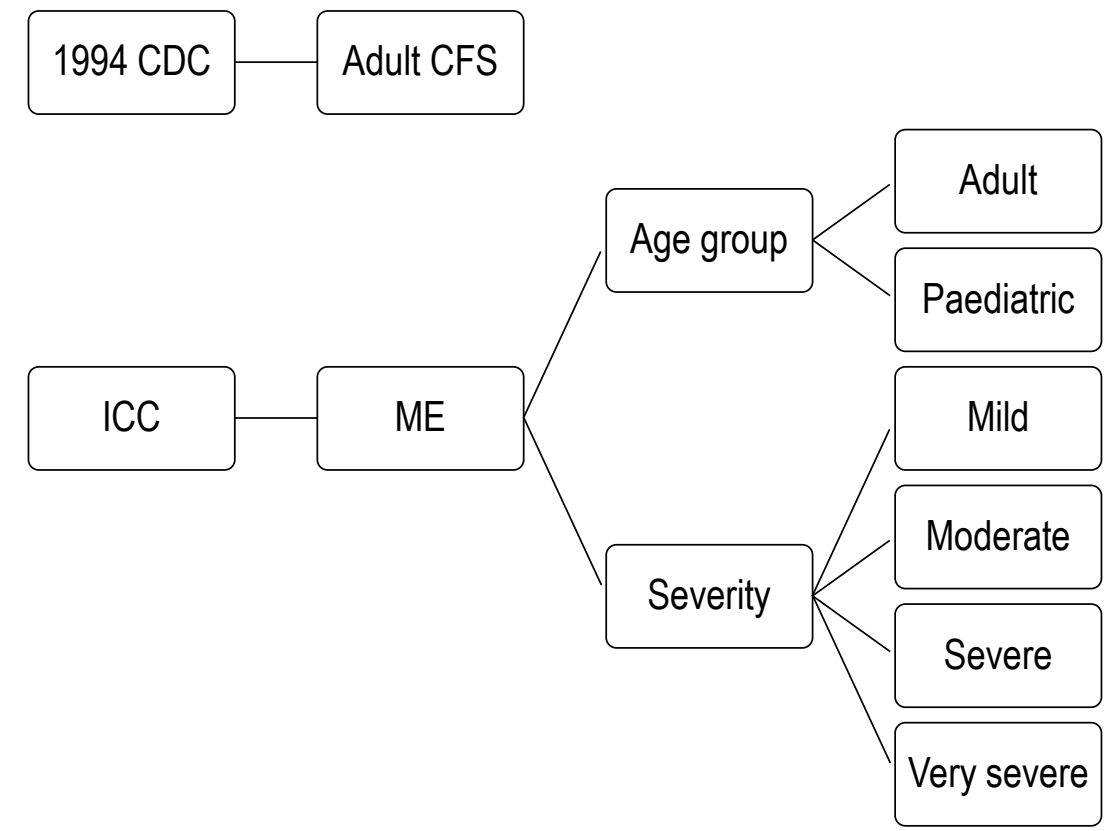

\section{Figure 1: The 1994 CDC for CFS vs. the ICC definition for ME}

The 1994 CDC [4] was devised in research for the selection of cases in adults. The ICC definition [5] was developed primarily for clinical diagnosis, but offers additional criteria for pediatric cases and severity for research.

Abbrev: CDC, Centers for Disease Control; ICC, International Consensus Criteria; CFS, Chronic Fatigue Syndrome; ME, Myalgic encephalomyelitis

The ICC [9] is the first definition to describe the illness in terms of severity, describing a substantial reduction in pre-illness activity levels as mild; a 50\% reduction in pre-illness activity levels as moderate; 
severe as mostly bedridden; and very severe as totally bedridden. How cases may differ in severity, has not been captured in prevalence research. Its classification of symptoms also enables research to examine how symptoms may vary in terms of pathophysiological dysfunction. The authors of the ICC [9] has also published a tool assist health professionals in its application known as the International Consensus Primer [57]. This could be of particular value in research, as an important issue has been inconsistent interpretation of previous definitions. Accordingly, the ICC [9] may be particularly affective in prevalence studies that are conducted in a primary care setting where clinicians are available to assess cases.

\section{Conclusion}

Available estimates of CFS prevalence are largely based on the 1994 CDC [4] definition that emphasize prolonged fatigue and a combination of broad non-specific symptoms. Recent developments in clinical definitions such as the CCC [5] and ICC [9] however, have moved away from this model of CFS and feature more specific symptoms that are multi-systemic in nature. This has received little attention in prevalence studies, despite findings that they may have improved effectiveness in selecting cases for research. This review proposes that a systematic approach be taken in future studies to adopt the ICC [9] definition in an effort to identify more specific cases of ME. The use of improved case definitions will contribute to more effective surveillance and provide further insight into the characteristics of the illness. 


\begin{tabular}{|c|c|c|c|c|c|c|c|}
\hline $\begin{array}{l}\text { Publ. } \\
\text { year }\end{array}$ & $\begin{array}{l}\text { First } \\
\text { Author }\end{array}$ & Country & Age & Samplea & Method ${ }^{b}$ & $\begin{array}{l}\text { Reported } \\
\text { prevalence } \\
(\%)\end{array}$ & $\begin{array}{l}\text { Case } \\
\text { definitionc }\end{array}$ \\
\hline 1990 & Lloyd [2] & Australia & all & $P$ & $P$ & 0.037 & Australian [2] \\
\hline 1991 & Ho-yen [51] & UK & all & $P$ & $P$ & 0.13 & Ho-Yen [6] \\
\hline 1992 & Price [50] & USA & $18 \leq$ & $P$ & $\mathrm{R}$ & $\begin{array}{l}0.0074 \\
0.3\end{array}$ & $\begin{array}{l}1988 \mathrm{CDC}^{*}[1] \\
1988 \mathrm{CDC}^{2}[1]\end{array}$ \\
\hline 1993 & Bates [49] & USA & $18 \leq$ & $P$ & $P$ & $\begin{array}{l}0.4 \\
1.0\end{array}$ & $\begin{array}{l}\text { Oxford [3] } \\
\text { Australian [2] }\end{array}$ \\
\hline 1993 & Gunn [48] & USA & $18 \leq$ & $\mathrm{P}$ & $\mathrm{P}$ & 0.003 & 1988 CDC [1] \\
\hline 1995 & Jason [40] & USA & $18 \leq$ & C & $P$ & 0.20 & 1988 CDC [1] \\
\hline 1995 & Lawrie [47] & UK & $18 \leq$ & $\mathrm{P}$ & $P$ & 0.56 & Oxford [3] \\
\hline 1997 & Dobbins [52] & US & $12-17$ & $P$ & $P$ & 2.7 & 1988 CDC [1] \\
\hline 1997 & Reyes [45] & USA & $18 \leq$ & $P$ & $P$ & 0.0052 & 1988 CDC [1] \\
\hline 1997 & Versluis [44] & Netherlands & $18 \leq$ & $P$ & $P$ & $\begin{array}{l}0.11 \\
1.50\end{array}$ & $\begin{array}{l}1988 \text { CDC [1] } \\
\text { Oxford [3] }\end{array}$ \\
\hline 1998 & Kawakami [39] & Japan & $18 \leq$ & C & $P$ & $\begin{array}{l}0 \\
1.50\end{array}$ & $\begin{array}{l}1988 \text { CDC [1] } \\
1994 \text { CDC [4] }\end{array}$ \\
\hline 1998 & Steele [38] & USA & $18 \leq$ & C & $P$ & 0.23 & 1994 CDC [4] \\
\hline 1999 & Jason [37] & USA & $18 \leq$ & C & $P$ & 0.42 & 1994 CDC [4] \\
\hline 2000 & Jordan [36] & US & $5-17$ & C & $\mathrm{P}$ & $\begin{array}{l}2.05 \\
0\end{array}$ & $\begin{array}{l}1994 \text { CDC [4] } \\
1988 \text { CDC [1] }\end{array}$ \\
\hline 2002 & Lindal [35] & Iceland & $19-75$ & C & $\mathrm{P}$ & $\begin{array}{l}4.80 \\
2.40 \\
1.40\end{array}$ & $\begin{array}{l}\text { Australian [2] } \\
\text { Oxford [3] } \\
1994 \text { CDC [4] }\end{array}$ \\
\hline 2003 & Reyes [33] & USA & $18-69$ & C & $P$ & 0.235 & 1994 CDC [4] \\
\hline 2003 & Chalder [34] & UK & $5-15$ & C & $P$ & 0.19 & 1994 CDC [4] \\
\hline 2004 & Jones [31] & US & $12-17$ & C & $P$ & 0.338 & 1994 CDC [4] \\
\hline 2004 & Bierl [32] & USA & $18-69$ & C & $P$ & 1.197 & 1994 CDC [4] \\
\hline 2005 & Kim [43] & Korea & $18 \leq$ & $P$ & $P$ & 0.60 & 1994 CDC [4] \\
\hline 2005 & Yiu [30] & Hong Kong & $20-50$ & C & $P$ & 6.40 & 1994 CDC [4] \\
\hline 2006 & Jordan [29] & US & $5-17$ & C & $\mathrm{P}$ & 0.06 & 1994 CDC [4] \\
\hline 2007 & Rimes [26] & UK & $11-15$ & C & $P$ & $\begin{array}{l}0.1 \\
0.5\end{array}$ & 1994 CDC [4] \\
\hline $\begin{array}{l}2007 \\
2007\end{array}$ & $\begin{array}{l}\text { Njoku [28] } \\
\text { Reeves [27] }\end{array}$ & $\begin{array}{l}\text { Nigeria } \\
\text { USA }\end{array}$ & $\begin{array}{l}18 \leq \\
18-59\end{array}$ & $\begin{array}{l}C \\
C\end{array}$ & $\begin{array}{l}P \\
P\end{array}$ & $\begin{array}{l}0.678 \\
2.54\end{array}$ & $\begin{array}{l}1994 \text { CDC [4] } \\
2005 \text { CDC [7] }\end{array}$ \\
\hline 2009 & Cho [42] & $\begin{array}{l}\text { Brazil } \\
\text { UK }\end{array}$ & $18-45$ & $\mathrm{P}$ & $P$ & $\begin{array}{l}1.60 \\
2.10\end{array}$ & 1994 CDC [4] \\
\hline 2010 & $\begin{array}{l}\text { van't Leven } \\
\text { [25] }\end{array}$ & Netherlands & $18 \leq$ & C & $P$ & 1.0 & 1994 CDC [4] \\
\hline 2011 & Bhui [24] & UK & $16-74$ & C & $\mathrm{R}$ & 2.30 & $1994 \mathrm{CDC}^{*}$ \\
\hline 2011 & $\begin{array}{l}\text { Hamaguchi } \\
\text { [23] }\end{array}$ & Japan & $20-78$ & C & $P$ & 1.00 & 1994 CDC [4] \\
\hline 2011 & Nijhof [2222] & Netherlands & $10-18$ & C & $P$ & $\begin{array}{l}0.111 \\
0.19\end{array}$ & $\begin{array}{l}1994 \text { CDC [4] } \\
1994 \text { CDC [4] }\end{array}$ \\
\hline 2011 & Nacul [41] & UK & $18-64$ & $P$ & $P$ & $\begin{array}{l}0.11 \\
0.03\end{array}$ & $\begin{array}{l}\text { CCC [5] } \\
\text { ECD [8] }\end{array}$ \\
\hline $\begin{array}{l}\text { a) } P, p \\
\text { and } P r \\
\text { *autho }\end{array}$ & mary care; C, & nmunity b) $P$ & finition & C, comr & nity c) CD & $\begin{array}{l}\text {, Centers fo } \\
\text { al Case Defi }\end{array}$ & $\begin{array}{l}\text { Disease Control } \\
\text { ion }\end{array}$ \\
\hline
\end{tabular}




\section{References}

1. Holmes GP, Kaplan JE, Gantz NM, Komaroff AL, Schonberger LB, Straus SE, et al. Chronic fatigue syndrome: a working case definition. Annals of internal medicine. 1988;108(3):387-9. Epub 1988/03/01.

2. Lloyd AR, Hickie I, Boughton CR, Spencer O, Wakefield D. Prevalence of chronic fatigue syndrome in an Australian population. The Medical journal of Australia. 1990;153(9):522-8. Epub 1990/11/05.

3. Sharpe MC, Archard LC, Banatvala JE, Borysiewicz LK, Clare AW, David A, et al. A report-chronic fatigue syndrome: guidelines for research. Journal of the Royal Society of Medicine. 1991;84(2):118-21. Epub 1991/02/01.

4. Fukuda K, Straus SE, Hickie I, Sharpe MC, Dobbins JG, Komaroff A. The chronic fatigue syndrome: a comprehensive approach to its definition and study. International Chronic Fatigue Syndrome Study Group. Annals of internal medicine. 1994;121(12):953-9. Epub 1994/12/15.

5. Carruthers BM, Jain AK, de Meirleir K, Paterson DL, Klimas N, Lerner AM, et al. Myalgic encephalomyelitis/chronic fatigue syndrome: Clinical working case definition, diagnostic and treatment protocols. Journal of Chronic Fatigue Syndrome. 2003;11(1):7-36.

6. Ho-Yen DO. Patient management of post-viral fatigue syndrome. The British journal of general practice : the journal of the Royal College of General Practitioners. 1990;40(330):37-9. Epub 1990/01/01.

7. Reeves WC, Wagner D, Nisenbaum R, Jones JF, Gurbaxani B, Solomon L, et al. Chronic fatigue syndrome--a clinically empirical approach to its definition and study. BMC medicine. 2005;3:19. Epub 2005/12/17.

8. Osoba T, Pheby D, Gray S, Nacul L. The Development of an Epidemiological Definition for Myalgic Encephalomyelitis/Chronic Fatigue Syndrome. Journal of Chronic Fatigue Syndrome. 2007;14(4):61-84.

9. Carruthers BM, van de Sande MI, De Meirleir KL, Klimas NG, Broderick G, Mitchell T, et al. Myalgic encephalomyelitis: International Consensus Criteria. Journal of internal medicine. 2011;270(4):327-38. Epub 2011/07/23.

10. Wagner D, Nisenbaum R, Heim C, Jones JF, Unger ER, Reeves WC. Psychometric properties of the CDC Symptom Inventory for assessment of chronic fatigue syndrome. Population health metrics. 2005;3:8. Epub 2005/07/27.

11. Ware JE, Jr., Sherbourne CD. The MOS 36-item short-form health survey (SF-36). I. Conceptual framework and item selection. Medical care. 1992;30(6):473-83. Epub 1992/06/11.

12. Smets EM, Garssen B, Bonke B, De Haes JC. The Multidimensional Fatigue Inventory (MFI) psychometric qualities of an instrument to assess fatigue. Journal of psychosomatic research. 1995;39(3):315-25. Epub 1995/04/01.

13. Wessely $\mathrm{S}$, Chalder T, Hirsch $\mathrm{S}$, Wallace $\mathrm{P}$, Wright $\mathrm{D}$. The prevalence and morbidity of chronic fatigue and chronic fatigue syndrome: a prospective primary care study. American journal of public health. 1997;87(9):1449-55. Epub 1997/10/07.

14. Bazelmans E, Vercoulen JH, Swanink CM, Fennis JF, Galama JM, van Weel C, et al. Chronic Fatigue Syndrome and Primary Fibromyalgia Syndrome as recognized by GPs. Family practice. 1999;16(6):602-4. Epub 2000/01/07.

15. Buchwald D, Umali P, Umali J, Kith P, Pearlman T, Komaroff AL. Chronic fatigue and the chronic fatigue syndrome: prevalence in a Pacific Northwest health care system. Annals of internal medicine. 1995;123(2):81-8. Epub 1995/07/15.

16. Minowa M, Jiamo M. Descriptive epidemiology of chronic fatigue syndrome based on a nationwide survey in Japan. Journal of epidemiology / Japan Epidemiological Association. 1996;6(2):75-80. Epub 1996/06/01. 
17. Jason LA, Wagner L, Rosenthal S, Goodlatte J, Lipkin D, Papernik M, et al. Estimating the prevalence of chronic fatigue syndrome among nurses. The American journal of medicine. 1998;105(3A):91S-3S. Epub 1998/10/28.

18. Farmer A, Fowler T, Scourfield J, Thapar A. Prevalence of chronic disabling fatigue in children and adolescents. The British journal of psychiatry : the journal of mental science. 2004;184:477-81. Epub 2004/06/03.

19. Huibers MJ, Kant IJ, Swaen GM, KasI SV. Prevalence of chronic fatigue syndrome-like caseness in the working population: results from the Maastricht cohort study. Occupational and environmental medicine. 2004;61(5):464-6. Epub 2004/04/20.

20. Kim SH, Lee K, Lim HS. Prevalence of chronic widespread pain and chronic fatigue syndrome in Korean livestock raisers. Journal of occupational health. 2008;50(6):525-8. Epub 2008/10/24.

21. Kang HK, Natelson BH, Mahan CM, Lee KY, Murphy FM. Post-traumatic stress disorder and chronic fatigue syndrome-like illness among Gulf War veterans: a population-based survey of 30,000 veterans. American journal of epidemiology. 2003;157(2):141-8. Epub 2003/01/11.

22. Nijhof SL, Maijer K, Bleijenberg G, Uiterwaal CS, Kimpen JL, van de Putte EM. Adolescent chronic fatigue syndrome: prevalence, incidence, and morbidity. Pediatrics. 2011;127(5):e1169-75. Epub 2011/04/20.

23. Hamaguchi M, Kawahito $\mathrm{Y}$, Takeda N, Kato T, Kojima T. Characteristics of chronic fatigue syndrome in a Japanese community population : chronic fatigue syndrome in Japan. Clinical rheumatology. 2011;30(7):895-906. Epub 2011/02/09.

24. Bhui KS, Dinos S, Ashby D, Nazroo J, Wessely S, White PD. Chronic fatigue syndrome in an ethnically diverse population: the influence of psychosocial adversity and physical inactivity. BMC medicine. 2011;9:26. Epub 2011/03/23.

25. van't Leven M, Zielhuis GA, van der Meer JW, Verbeek AL, Bleijenberg G. Fatigue and chronic fatigue syndrome-like complaints in the general population. European journal of public health. 2010;20(3):251-7. Epub 2009/08/20.

26. Rimes KA, Goodman R, Hotopf M, Wessely S, Meltzer H, Chalder T. Incidence, prognosis, and risk factors for fatigue and chronic fatigue syndrome in adolescents: a prospective community study. Pediatrics. 2007;119(3):e603-9. Epub 2007/03/03.

27. Reeves WC, Jones JF, Maloney E, Heim C, Hoaglin DC, Boneva RS, et al. Prevalence of chronic fatigue syndrome in metropolitan, urban, and rural Georgia. Population health metrics. 2007;5:5. Epub 2007/06/15.

28. Njoku MG, Jason LA, Torres-Harding SR. The prevalence of chronic fatigue syndrome in Nigeria. Journal of health psychology. 2007;12(3):461-74. Epub 2007/04/19.

29. Jordan $\mathrm{E}$. Prevalence of pediatric chronic fatigue syndrome in a community-based sample. Journal of Chronic Fatigue Syndrome. 2006;13(2):75-8.

30. Yiu YM, Qiu MY. [A preliminary epidemiological study and discussion on traditional Chinese medicine pathogenesis of chronic fatigue syndrome in Hong Kong]. Zhong xi yi jie he xue bao = Journal of Chinese integrative medicine. 2005;3(5):359-62. Epub 2005/09/15.

31. Jones JF, Nisenbaum R, Solomon L, Reyes M, Reeves WC. Chronic fatigue syndrome and other fatiguing illnesses in adolescents: a population-based study. The Journal of adolescent health : official publication of the Society for Adolescent Medicine. 2004;35(1):34-40. Epub 2004/06/15.

32. Bierl C. Regional distribution of fatiguing illnesses in the United States: a pilot study. Population health metrics. 2004;2(1):1.

33. Reyes M, Nisenbaum R, Hoaglin DC, Unger ER, Emmons C, Randall B, et al. Prevalence and incidence of chronic fatigue syndrome in Wichita, Kansas. Archives of internal medicine. 2003;163(13):1530-6. Epub 2003/07/16.

34. Chalder T, Goodman R, Wessely S, Hotopf M, Meltzer H. Epidemiology of chronic fatigue syndrome and self reported myalgic encephalomyelitis in 5-15 year olds: cross sectional study. Bmj. 2003;327(7416):654-5. Epub 2003/09/23. 
35. Lindal E, Stefansson JG, Bergmann S. The prevalence of chronic fatigue syndrome in Iceland a national comparison by gender drawing on four different criteria. Nordic journal of psychiatry. 2002;56(4):273-7. Epub 2002/12/10.

36. Jordan E. Prevalence of fatigue and chronic fatigue syndrome-like illness in children and adolescents. Journal of Chronic Fatigue Syndrome. 2000;6(1):3-21.

37. Jason LA, Richman JA, Rademaker AW, Jordan KM, Plioplys AV, Taylor RR, et al. A community-based study of chronic fatigue syndrome. Archives of internal medicine. 1999;159(18):212937. Epub 1999/10/20.

38. Steele L, Dobbins JG, Fukuda K, Reyes M, Randall B, Koppelman M, et al. The epidemiology of chronic fatigue in San Francisco. The American journal of medicine. 1998;105(3A):83S-90S. Epub 1998/10/28.

39. Kawakami N, Iwata N, Fujihara S, Kitamura T. Prevalence of chronic fatigue syndrome in a community population in Japan. The Tohoku journal of experimental medicine. 1998;186(1):33-41. Epub 1999/01/23.

40. Jason LA, Taylor R, Wagner L, Holden J, Ferrari JR, Plioplys AV, et al. Estimating rates of chronic fatigue syndrome from a community-based sample: a pilot study. American journal of community psychology. 1995;23(4):557-68. Epub 1995/08/01.

41. Nacul LC, Lacerda EM, Pheby D, Campion P, Molokhia M, Fayyaz S, et al. Prevalence of myalgic encephalomyelitis/chronic fatigue syndrome (ME/CFS) in three regions of England: a repeated cross-sectional study in primary care. BMC medicine. 2011;9:91. Epub 2011/07/29.

42. Cho HJ, Menezes PR, Hotopf M, Bhugra D, Wessely S. Comparative epidemiology of chronic fatigue syndrome in Brazilian and British primary care: prevalence and recognition. The British journal of psychiatry : the journal of mental science. 2009;194(2):117-22. Epub 2009/02/03.

43. Kim CH, Shin $\mathrm{HC}$, Won $\mathrm{CW}$. Prevalence of chronic fatigue and chronic fatigue syndrome in Korea: community-based primary care study. Journal of Korean medical science. 2005;20(4):529-34. Epub 2005/08/16.

44. Versluis RG, de Waal MW, Opmeer C, Petri H, Springer MP. [Prevalence of chronic fatigue syndrome in 4 family practices in Leiden]. Nederlands tijdschrift voor geneeskunde. 1997;141(31):1523-

6. Epub 1997/08/02. Prevalentie van chronische-vermoeidheidsyndroom in 4 huisartspraktijken in de regio Leiden.

45. Reyes M, Gary HE, Jr., Dobbins JG, Randall B, Steele L, Fukuda K, et al. Surveillance for chronic fatigue syndrome--four U.S. cities, September 1989 through August 1993. MMWR CDC surveillance summaries : Morbidity and mortality weekly report CDC surveillance summaries / Centers for Disease Control. 1997;46(2):1-13. Epub 1997/02/21.

46. Dobbins JG. The prevalence of chronic fatiguing illnesses among adolescents in the United States. Journal of Chronic Fatigue Syndrome. 1997;3(2):15-27.

47. Lawrie SM, Pelosi AJ. Chronic fatigue syndrome in the community. Prevalence and associations. The British journal of psychiatry : the journal of mental science. 1995;166(6):793-7. Epub 1995/06/01.

48. Gunn WJ, Connell DB, Randall B. Epidemiology of chronic fatigue syndrome: the Centers for Disease Control Study. Ciba Foundation symposium. 1993;173:83-93; discussion -101. Epub 1993/01/01.

49. Bates DW, Schmitt W, Buchwald D, Ware NC, Lee J, Thoyer E, et al. Prevalence of fatigue and chronic fatigue syndrome in a primary care practice. Archives of internal medicine. 1993;153(24):275965. Epub 1993/12/27.

50. Price RK, North CS, Wessely S, Fraser VJ. Estimating the prevalence of chronic fatigue syndrome and associated symptoms in the community. Public health reports. 1992;107(5):514-22. Epub 1992/09/01. 
51. Ho-Yen DO, McNamara I. General practitioners' experience of the chronic fatigue syndrome. The British journal of general practice : the journal of the Royal College of General Practitioners. 1991;41(349):324-6. Epub 1991/08/01.

52. Dobbins JG, Randall B, Reyes M, Steete L, Livens EA, Reeves WC. The prevalence of chronic fatiguing illnesses among adolescents in the United States. Journal of Chronic Fatigue Syndrome. 1997;3(2):15-27.

53. Matthews DA, Lane TJ, Manu P. Definition of the chronic fatigue syndrome. Annals of internal medicine. 1988;109(6):511-2. Epub 1988/09/15.

54. Straus SE. Defining the chronic fatigue syndrome. Archives of internal medicine. 1992;152(8):1569-70. Epub 1992/08/01.

55. Komaroff AL, Buchwald DS. Chronic fatigue syndrome: an update. Annual review of medicine. 1998;49:1-13. Epub 1998/03/24.

56. Jason LA, Brown A, Clyne E, Bartgis L, Evans M, Brown M. Contrasting case definitions for chronic fatigue syndrome, Myalgic Encephalomyelitis/chronic fatigue syndrome and myalgic encephalomyelitis. Evaluation \& the health professions. 2012;35(3):280-304. Epub 2011/12/14.

57. Carruthers BM, van de Sande M, De Meirleir K, Klimas N, G. B, T. M, et al. Myalgic Encephalomyelitis - Adult \& Paediatric: International Consensus Primer for Medical Practioners. In: Carruthers BM, van de Sande M, editors. Canada: Carruthers \& van de Sande; 2012.

58. Reeves WC, Lloyd A, Vernon SD, Klimas N, Jason LA, Bleijenberg G, et al. Identification of ambiguities in the 1994 chronic fatigue syndrome research case definition and recommendations for resolution. BMC health services research. 2003;3(1):25. Epub 2004/01/02.

59. Kennedy G, Abbot NC, Spence V, Underwood C, Belch JJ. The specificity of the CDC-1994 criteria for chronic fatigue syndrome: comparison of health status in three groups of patients who fulfill the criteria. Annals of epidemiology. 2004;14(2):95-100. Epub 2004/03/17.

60. Jason LA, Taylor RR, Carrico AW. A community-based study of seasonal variation in the onset of chronic fatigue syndrome and idiopathic chronic fatigue. Chronobiology international. 2001;18(2):315-9. Epub 2001/05/31.

61. Jason LA, Corradi K, Torresharding S. Toward an empirical case definition of CFS. Journal of Social Service Research. 2007;34(2):43-54.

62. Sullivan PF, Pedersen NL, Jacks A, Evengard B. Chronic fatigue in a population sample: deifnitions and heterogeneity. Psychological medicine. 2005;35(9):1337-48.

63. Jason LA, Torres-Harding SR, Jurgens A, Helgerson J. Comparing the Fukuda et al. criteria and the Canadian case definition for chronic fatigue syndrome. Journal of Chronic Fatigue Syndrome. 2004;12(1):37-52.

64. Jason LA, Richman JA. How science can stigmatize: the case of chronic fatigue syndrome. Journal of Chronic Fatigue Syndrome. 2007;14(4):85-103.

65. Jason LA, Najar N, Porter N, Reh C. Evaluating the Centers for Disease Control's empirical chronic fatigue syndrome case definition. Journal of Disability Policy Studies. 2009;20(2):93-100.

66. Jason LA, Skendrovic B, Furst J, Brown A, Weng A, Bronikowski C. Data mining: comparing the empiric CFS to the Canadian ME/CFS case definition. Journal of clinical psychology. 2011;68(1):419.

67. Jason LA, Jordan K, Miike T, Bell DS, Lapp C, Torres-Harding S, et al. A pediatric case definition for myalgic encephalomyelitis and chronic fatigue syndrome. Journal of Chronic Fatigue Syndrome. 2006;13(2-3):1-44.

68. Jason L, Porter N, Shelleby E, Till L, Bell DS, Lapp CW, et al. Severe versus Moderate criteria for the new pediatric case definition for ME/CFS. Child psychiatry and human development. 2009;40(4):609-20. Epub 2009/06/11. 